\title{
Article \\ Exploring the Challenges Posed by Regulations for the Use of Drones in Agriculture in the African Context
}

\author{
Matthew Ayamga (D), Bedir Tekinerdogan *(D) and Ayalew Kassahun $(\mathbb{D}$ \\ Information Technology Group, Wageningen University, P.O. Box 8130, 6700 EW Wageningen, The Netherlands; \\ matthew.ayamga@wur.nl (M.A.); ayalew.kassahun@wur.nl (A.K.) \\ * Correspondence: bedir.tekinerdogan@wur.nl; Tel.: +31-(0)-317-485-477
}

Citation: Ayamga, M.; Tekinerdogan

B.; Kassahun, A. Exploring the Challenges Posed by Regulations for the Use of Drones in Agriculture in the African Context. Land 2021, 10, 164. https://doi.org/10.3390/ land10020164

Academic Editor: Assem Abu Hatab Received: 23 December 2020

Accepted: 3 February 2021

Published: 6 February 2021

Publisher's Note: MDPI stays neutral with regard to jurisdictional claims in published maps and institutional affiliations.

Copyright: (c) 2021 by the authors. Licensee MDPI, Basel, Switzerland. This article is an open access article distributed under the terms and conditions of the Creative Commons Attribution (CC BY) license (https:// creativecommons.org/licenses/by/ $4.0 /)$.

\begin{abstract}
Global food demands have led to the rapid introduction of Information Communication Technology (ICT) innovations in the agriculture sector-one such innovation is drone technology. Drones are used in precision agriculture, including aerial observation, sensing, and the spraying of pesticides. Regulations on the use of drones are necessary because drones can violate privacy rules, data protection rights, and public peace. However, many African countries have either very restrictive regulations, or no proper regulation in place, making the process of acquiring a license for drone operation cumbersome. In this study, we present the results of a literature review that explores the current drone regulations in Sub-Saharan Africa and the results of a systematic literature review (SLR) and survey study whereby we have interviewed the relevant stakeholders, in order to understand the challenges posed by the regulations to the effective use of drones for agriculture. The results indicate that the regulations contain about 40 to 85 per cent of the provisions of the International Civil Aviation Organization (ICAO) manual on Remotely Piloted Aircraft Systems (RPASs). In addition, whilst the SLR focused on the technology, safety, ethics and regulatory hurdles towards drones, the interviewees focused on the need for skill and awareness among the responsible authorities to enforce regulations, and the need for sustainability and participatory process in defining regulations.
\end{abstract}

Keywords: Remotely Piloted Aircraft Systems; International Civil Aviation Organization; drones in agriculture; drone regulations in Africa

\section{Introduction}

Drone technology and usage has been increasing within the last decade, especially in the agriculture sector [1]. Compared to much larger manned aircrafts, drones can survey agricultural land without the inherent safety risks and high costs. Drones-also referred to as Unmanned Aerial Vehicles (UAVs) or Remotely Piloted Aircraft Systems (RPAS) — are typically used to obtain real-time imagery and sensor data from farm fields which cannot be quickly or easily accessed on foot or by a vehicle [2]. Through crop health imaging, integrated GIS mapping and minimizing the need to physically go through the field, drones could play a vital role in the decision making and management process contributing to increased yield and reduced cost. This would increase the efficiency and effectiveness of some management actions. In addition, drones can be used in monitoring rugged areas, tracking down illegal activities, and observing forest fires and other natural disasters [3]. Drones also attract educated youth to venture into agricultural service enterprises, thus generating job opportunities and improving farmers' returns on investments [4].

Despite the obvious advantages, increased drone flights have heightened public concerns regarding safety and privacy issues [5]. According to [6], UAVs are new airspace objects that pose a potential risk to other users of the airspace and to businesses and individuals on the ground. As a result, a growing number of countries are establishing regulations in order to minimize safety and privacy risks that UAVs pose to humans and their property [7]. 
In Sub-Saharan Africa, some countries already have regulations in place, some others are grappling with legal issues of UAVs, and a few are not in the process of developing regulations [8]. The purpose of this study is, therefore, to explore the challenges regulations pose in using drones for agriculture in Africa, with a particular focus on Sub-Saharan Africa. For this purpose, the research questions (RQs) this study will answer include:

RQ1: What are the current regulations in place for flying drones in Africa?

RQ2: What are the challenges of flying or using drones with regard to regulations?

To answer RQ1, we resorted to two major databases of drone regulations to extract the regulations' texts, and carefully reviewed them. To answer RQ2, we adopted a systematic literature review (SLR) together with a survey study. The literature review explores the current drone regulations in Sub-Saharan Africa and the related scientific literature. For the survey study, we have interviewed the relevant stakeholders in order to understand the challenges, posed by the regulations, to the effective use of drones for agriculture. Findings from this study would help to develop a tailored drone policy framework for Africa considering that the African Union (AU) has no drone policy framework at the regional level to expedite individual countries' drone regulation development. Through the policy development process, relevant stakeholders could be involved, and they can communicate their goals, objectives, and preferences to the policymakers who must then decide on the policies to be adopted [9]. Furthermore, potential drone users would be made aware of existing drone regulations across Africa.

Before moving on to the adopted methodologies to answer our RQs, we will present a little background on agricultural drones. Drones, formally known as Unmanned Aerial Vehicles (UAVs) or a Remotely Piloted Aircraft Systems (RPASs), according to the definition by the International Civil Aviation Organization (ICAO) [10], are aircrafts that are operated without a human pilot aboard. A drone that is combined with the ground-based controller, and the communication system between the two, is referred to as an Unmanned Aircraft System (UAS) or a small Unmanned Aircraft System (sUAS). As shown in Figure 1, drones are classified into two functional categories: fixed wing and rotor (rotating wings) drones [1,11]. The fixed wing drones generates lifts as it moves enabling it to sustain velocity through the air whereas the rotor is highly maneuverable and can hover and rotate with a flight controller. Both have specific advantages and disadvantages (Table 1) in relation to weight, stability, speed, flight duration, and control [1].

Table 1. Advantages and disadvantages of fixed wing and rotor drones.

\begin{tabular}{|c|c|}
\hline FIXED WING & ROTOR \\
\hline Advantage & Advantage \\
\hline $\begin{array}{l}\text { Have larger payload capacity, higher top speed, longer } \\
\text { flight times and longer range compared to rotor systems } \\
\text { with similar battery capacity. } \\
\text { For these reasons, fixed-wing systems are particularly } \\
\text { useful for collecting data over a large area. } \\
\text { Disadvantage }\end{array}$ & $\begin{array}{l}\text { - Manual takeoff, flying and landing are easy to learn, and } \\
\text { some models have built-in "sense-and-avoid" technology. } \\
\text { There are many low-cost models on the market, along with } \\
\text { more costly units with larger payload capacity and/or } \\
\text { flight time. } \\
\quad \text { Disadvantage }\end{array}$ \\
\hline $\begin{array}{l}\text { Compared to rotor UAS, fixed-wing systems are less } \\
\text { maneuverable, they require more open space for landing } \\
\text { and more skill to pilot, and they tend to be several times } \\
\text { more expensive than similar-grade rotor systems. }\end{array}$ & $\begin{array}{l}\text { - } \quad \text { Shorter range and flight time compared to fixed-wing. } \\
\text { - } \quad \text { Fixed wings are the main drawbacks to rotorcraft. }\end{array}$ \\
\hline
\end{tabular}




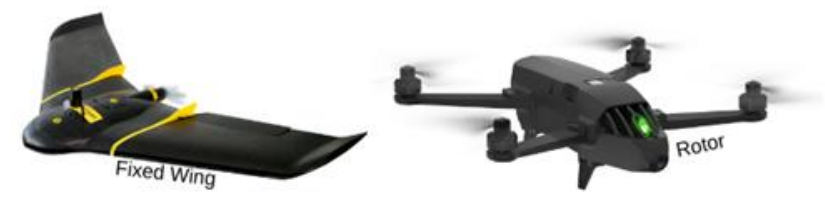

Figure 1. The fixed-wing eBee Sequoia (SQ) and the Parrot Anafi rotor drones from Parrot Group: picture concept adopted and modified from [1].

Research in drone technology comprises a diverse array of aspects including technology, privacy rights, safety and regulations [12]. Misuse (e.g., terrorism) and military use of drones are also significant public concerns and, thus, a focus for research [13].

According to [14], there are different regulations depending on the concept of operation of the UAVs. With this in mind, we present the feature diagram (Figure 2) of UAVs to show the different combinations of functions a drone can have. Though Figure 2 does not describe an exhaustive feature of a drone, we aim to use it to illustrate an example of a possible combination of functions of a drone at a given point in time. For instance, we could have a rotor that is controlled manually, with an RGB camara attached, monitored with a smart phone for surveillance on a farm, and with a security alert component to warn against flying in an unauthorized zone.

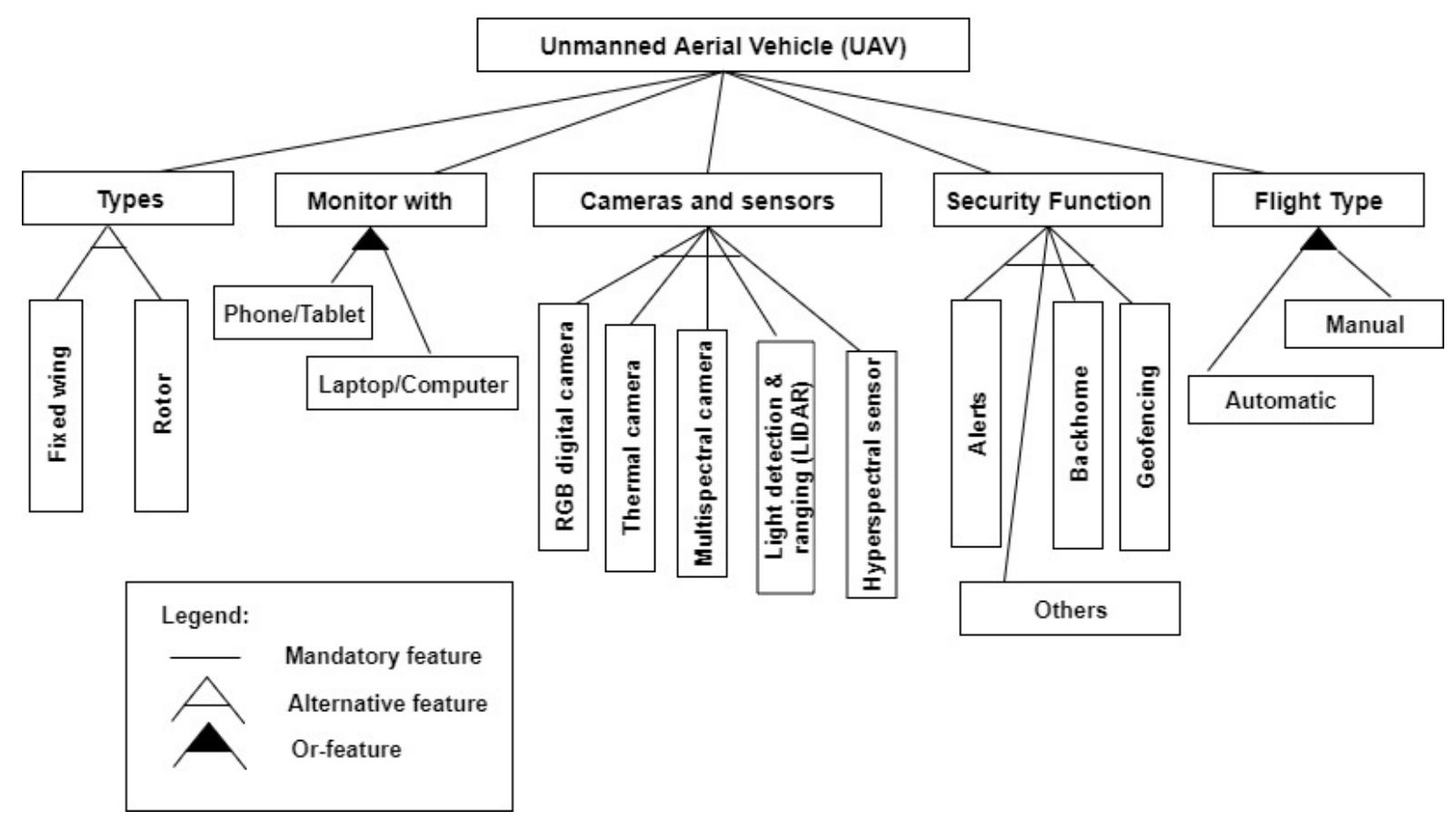

Figure 2. Feature diagram for Unmanned Aerial Vehicle (drone).

Regulation of civilian airspace in Africa is the responsibility of the National Civil Aviation Authorities (NCAAs), which control both the development and enactment of regulations [15]. NCAAs are national government statutory authorities and, hence, are the primary regulators of drone usage within the national airspace [15]. NCAAs' responsibilities include:

- Checking on airborne and ground-based equipment that can affect flight safety.

- Pilot licensing.

- Issuing flight permits.

- Defining standards for UAV operations and minimum requirements for operating different UAV classes based on take-off mass and size. 


\section{Research Methodology}

In this section, we present the SLR processes followed and the survey study conducted. The documents regarding drone regulations were derived from the following two online sources: www.rpas-regulations.com (world's largest online repository dedicated to dronerelated regulatory matters), and www.droneregulations.info (global drone regulations database). These sources provide information on whether or not a particular country has a drone regulation in place, and contain either the regulatory document or a link to it.

We followed the SLR protocol of [16]. The protocol includes the following steps: specifying the research questions, identification of literature databases, defining search keywords and scope, searching the databases, selecting primary studies, and performing quality assessment, data extraction, and synthesis. The research questions are presented in the introduction. We identified and limited the literature databases to Scopus and Web of Science. We derived search keywords from the research questions and limited the scope of the search to studies conducted in the past five years: from 2014 to 2018. The search was conducted automatically and manually in September 2018.

The search keywords were used to perform the automated search, while the manual search was done through snowballing. The search string used was "((drone regulation* OR drone policy* OR UAV regulation* OR UAV policy*) AND (drone challenges* OR UAV challenges) $)^{\prime \prime}$. Figure 3 summarizes the review protocol followed.

The search resulted in 778 research papers (Table 2). Since the automated process of searching provides many irrelevant studies, we applied the following exclusion criteria in order to filter the relevant studies.

1. Abstract or title does not discuss drones.

2. The paper is not in English.

3. Drones not a focus, not mentioned, or mentioned not in relation to the study context.

4. The paper does not discuss the challenges of using drones.

5. Duplicates that have already undergone the exclusion process.

6. When two versions of the same paper exist, the extended version is used and the short version is excluded.

Table 2. Search results and study selection.

\begin{tabular}{cccc}
\hline Source & Search Strategy & Found $^{[\mathbf{a}]}$ & Selected $^{[\mathbf{b}]}$ \\
\hline Web of science & Automated & 30 & 2 \\
Scopus & Automated & 448 & 2 \\
- & Snowball & 300 & 5 \\
\hline Total & & 778 & 9 \\
\hline
\end{tabular}

[a] Number of included studies after applying search query. ${ }^{[b]}$ Number of included studies after applying exclusion criteria. 


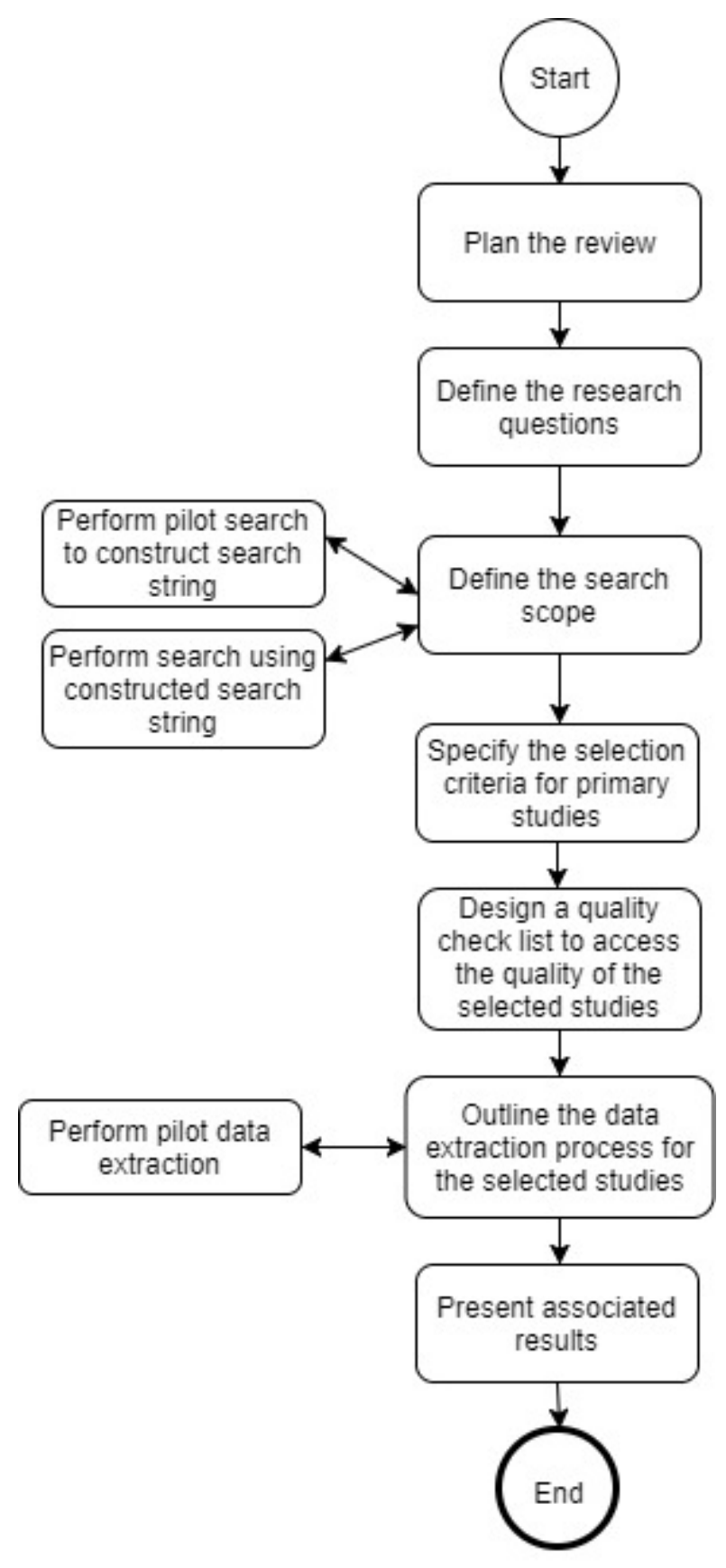

Figure 3. Systematic literature review protocol.

The application of the exclusion criteria resulted in only 9 papers being selected for further quality assessment. Many of the excluded papers were mainly about drone applications to specific crops and simulated experiments of drone delivery systems, and others mentioned the term "drone" but did not focus on the drone technology.

The 9 selected studies were further assessed based on their quality. The checklist is adapted from [17] and modified to suit the scope and aim for conducting the SLR in this study. The quality scales are: zero (0) to stand for "bad" quality, 0.5 for "neutral" and 1 for "good", depending on how well the selected studies relate to the specific quality checklist questions. Table 3 presents the quality checklist. The analysis of the extracted data from the 9 studies was based on thematic topics like: authorship, year of publication, journal, etc. Moreover, the extraction of the challenges posed by regulations (Table 4) was carefully conducted following the trends that were presented in the studies, and then we organized these challenges in a logical flow. 
Table 3. Quality checklist.

\begin{tabular}{|c|c|c|}
\hline Category & Quality Criterion ID & Questions \\
\hline \multirow{3}{*}{ Clarity } & Q1 & Is the study aim stated clearly? \\
\hline & Q2 & Is the reporting clear and systematic? \\
\hline & Q3 & Are the findings clearly presented? \\
\hline \multirow{2}{*}{$\begin{array}{l}\text { Generalizability of } \\
\text { the study }\end{array}$} & Q4 & \multirow{2}{*}{$\begin{array}{c}\text { Is the study independent of a domain? } \\
\text { Is the scope of drone technology } \\
\text { comprehensive? }\end{array}$} \\
\hline & Q5 & \\
\hline \multirow{3}{*}{ Coherency of results } & Q6 & \multirow{3}{*}{$\begin{array}{l}\text { Is the study clear in describing which } \\
\text { challenges are analyzed? } \\
\text { Are the sources of information clearly stated? } \\
\text { Are study questions clear and coherent? }\end{array}$} \\
\hline & Q7 & \\
\hline & Q8 & \\
\hline \multirow[b]{2}{*}{ Completeness } & Q9 & \multirow{2}{*}{$\begin{array}{c}\text { Are all the research questions addressed? } \\
\text { Is the conclusion given in accordance with } \\
\text { the study goals? }\end{array}$} \\
\hline & Q10 & \\
\hline
\end{tabular}

Moving on to the survey study, a qualitative interview guide was developed to help conduct interviews with respondents that can provide an in-depth understanding of the regulations, the processes of acquiring permission and operating drones, or the challenges posed by regulations in general.

We, therefore, used the results from the SLR to guide the formulation of the qualitative interview protocol. In a survey study, the researcher seeks knowledge from the respondent's point of view [18]. Figure 4 presents the survey protocol followed.

Table 4. Challenges identified from SLR.

\begin{tabular}{ccc}
\hline$\#^{[\mathbf{a}]}$ & Description & Reference \\
\hline 1 & Gaps in the respective laws and regulations governing drone use & {$[5,6,19]$} \\
2 & Lack of awareness about relevant regulations regarding data & {$[1,6,20,21]$} \\
3 & protection and privacy & {$[19]$} \\
4 & Enforcement and implementation challenges & {$[20,22]$} \\
5 & Ethical procurement and misuse of drones. & {$[7,23]$} \\
\hline
\end{tabular}

[a] Challenge.

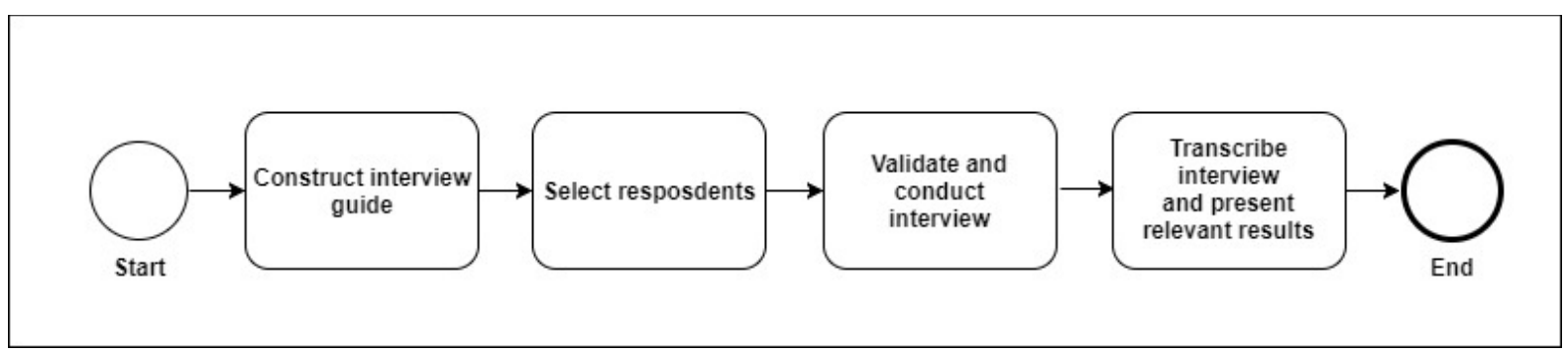

Figure 4. Survey protocol.

We employed the snowball technique to obtain the stakeholders who can respond to the interview questions to help answer RQ2. We identified one interviewee first, who then provided us with the contact information for the remaining interviewees. As a shortcoming of our paper, we had only 4 interviewees. Before going on to conduct the interviews with the respondents, it is prudent to validate the guide to make sure it will be able to provide the needed answers for the research questions to help achieve the objective of conducting the interviews. To begin the validation process, a draft version of the interview guide was reviewed within the research team and the feedback helped to further improve the quality of the guide. This was sorted to establish context validity. 
Again, a pilot interview was conducted to ascertain the flow of the questions, which enabled irrelevant questions to be removed and a final version of the guide was then approved. Administration of the interview guide was conducted in-person with interviewee 1 in Ghana, while the other interview sessions were conducted through skype. The reason for this was that the first author went to Ghana for a holiday and used the opportunity to interview interviewee 1. During the in-person interview, an audio recorder was used to record the discussion, which was later transcribed, and the data were extracted. The other interviews through skype were also recorded and transcribed, and the data were extracted.

\section{Results}

In the African context, the countries with regulations include South Africa, Botswana and Zimbabwe (regulations published in 2015); Ghana, Nigeria, Cameroon, Gabon and Senegal (regulations published in 2016); Namibia, Zambia, Malawi, Tanzania and Madagascar (regulations published in 2017); and Rwanda and Benin (regulations published in 2018). Kenya had a drone regulation, but the document was retracted for discussion in parliament due to high tax resulting from the importing of drones during the period of this research.

\subsection{SLR Results}

The analysis of the results of the SLR revealed that after the quality assessment, one study received a score of nine, four studies received a score of 7.5, 1 study received a score of seven, and three studies received a score of 6.5 (Table 5).

The analysis of the included studies resulted in the identification of five major challenges in using drones. These challenges are listed in Table 4 and elaborated thereafter.

Gaps in the respective laws and regulations governing drone use:

The lack of proper regulation and enforcement continues to be the main limitation for the rapid adoption of drones. Drones can be operated in public spaces and are able to capture images and sound from places that are not traditionally available to the public, and thus drones disrupt the expectations of reasonable privacy. This gap in the law allows for the possibility of unwarranted surveillance without fear of repercussions [19].

When regulations are available, the regulations focus upon three key aspects: (1) targeting the regulated use of airspace by UAVs; (2) imposing operational limitations; and (3) tackling the administrative procedures of flight permissions, pilot licenses and data collection authorization. However, the remaining problems for regulations to tackle include: (1) gaps in the respective laws and regulations governing the use of drones, and (2) the influence of various interest groups. The current state of drone regulatory frameworks, and the heterogeneity of national drone regulations, shows the influence of various interest groups. A key challenge appears to be finding an optimum balance between what the various actors are demanding to be included in the regulations, allowing for innovation on the one hand, but, at the same time, ensuring recognition and support for safety, fundamental human rights and civil liberties [6].

Even if appropriate regulations are in place, technological, regulatory, workload and coordination challenges affect the ability to operate drones safely and routinely in national airspaces. When lives could be at risk, authorities focus attention on addressing this safety challenge first, resulting in regulations with sweeping prevention of the commercial use of drones [5]. 
Table 5. Summary of included studies.

\begin{tabular}{|c|c|c|c|}
\hline Number & Author & Title & Journal \\
\hline 1 & $\begin{array}{l}\text { Damian Tobor, Jacek Barcik, Piotr } \\
\text { Czech }\end{array}$ & $\begin{array}{l}\text { Legal aspects of air transport safety } \\
\text { and the use of drones }\end{array}$ & $\begin{array}{c}\text { Scientific Journal of Silesian } \\
\text { University of Technology. Series } \\
\text { Transport (SJUST.ST) }\end{array}$ \\
\hline 2 & $\begin{array}{l}\text { Hogan Sean, Kelly Maggi, Stark } \\
\text { Brandon, \& Chen YangQuan }\end{array}$ & $\begin{array}{l}\text { Unmanned aerial systems for } \\
\text { agriculture and natural resources. }\end{array}$ & California Agriculture Journal \\
\hline 3 & Luppicini, Rocci \& So, Arthur. & $\begin{array}{l}\text { A technoethical review of commercial } \\
\text { drone use in the context of } \\
\text { governance, ethics, and privacy }\end{array}$ & $\begin{array}{l}\text { Technology in } \\
\text { Society-Journal-Elsevier }\end{array}$ \\
\hline 4 & $\begin{array}{c}\text { Stöcker Claudia, Bennett Rohan, Nex } \\
\text { Francesco, Gerke Markus, \& } \\
\text { Zevenbergen Jaap. }\end{array}$ & $\begin{array}{c}\text { Review of the current state of UAV } \\
\text { regulations }\end{array}$ & $\begin{array}{l}\text { Remote Sensing Journal from } \\
\text { MDPI }\end{array}$ \\
\hline 5 & $\begin{array}{c}\text { Rao Bharat, Gopi Ashwin Goutham, } \\
\text { \& Maione Romana. }\end{array}$ & $\begin{array}{c}\text { The societal impact of commercial } \\
\text { drones }\end{array}$ & $\begin{array}{c}\text { Technology in } \\
\text { Society-Journal-Elsevier }\end{array}$ \\
\hline 6 & $\begin{array}{l}\text { Berie Habitamu Taddese, \& Burud } \\
\text { Ingunn. }\end{array}$ & $\begin{array}{l}\text { Application of unmanned aerial } \\
\text { vehicles in earth resources } \\
\text { monitoring: focus on evaluating } \\
\text { potentials for forest monitoring in } \\
\text { Ethiopia }\end{array}$ & $\begin{array}{l}\text { European Journal of Remote } \\
\text { Sensing-Taylor \& Francis }\end{array}$ \\
\hline 7 & Gilman Daniel & $\begin{array}{l}\text { Unmanned aerial vehicles in } \\
\text { humanitarian response }\end{array}$ & $\begin{array}{c}\text { United Nations Office for the } \\
\text { Coordination of Humanitarian } \\
\text { Affairs (UNOCHA) }\end{array}$ \\
\hline 8 & Freeman, P. K., \& Freeland, R. S. & $\begin{array}{l}\text { Politics \& technology: US polices } \\
\text { restricting unmanned aerial systems } \\
\text { in agriculture. }\end{array}$ & Food Policy-Elsevier \\
\hline 9 & Clarke, R., \& Moses, L. B. (2014). & $\begin{array}{l}\text { The regulation of civilian drones' } \\
\text { impacts on public safety. }\end{array}$ & $\begin{array}{l}\text { Computer law \& security } \\
\text { review-Elsevier }\end{array}$ \\
\hline
\end{tabular}

Lack of awareness about relevant regulations, data protection and privacy rules:

The lack of awareness about the applicability of data protection and privacy rules remains a challenge [6]. Understanding the relevant regulations and issues of safety when piloting drones is part of the variety of practical challenges in using the drone technology effectively [1]. From the perspective of [21], improper enforcement of relevant regulations is due to the lack of educational and training facilities for officials. In addition, the difficulty in communicating with drone manufacturers and retailers, the lack of professionals who can assess risks, and devise and implement appropriate safeguards, and the difficulty in establishing appropriate commercial arrangements, maintenance services, and public liability insurance, create major challenges in operating drones.

The legal aspect is one of the biggest challenges of expanding the use of drones. Regulators in developing countries are wrestling with how to deal with drones' capacity to observe private property and capture personal information [20].

\section{Enforcement and implementation challenges:}

Even with regulations in place, the inability to enforce and implement them remains a challenge to the adoption of drones. The administration of rules is usually coordinated by local law enforcement agencies, but there is a total disconnection of local, state and federal laws. Unregistered drones result in legal actions, but managing registrations has remained a challenge. In addition, drone technology has far outpaced the regulatory process. Moreover, due the relatively small impact of the use of civilian drones, the implementation of regulations is often delayed [19].

\section{Ethical procurement and misuse of drones:}

The ban of drones in some African countries is a measure that might be taken because of the observed challenges relating to the misuse of the technology. Drones could play an important role in complex humanitarian emergency services as they can be used for surveillance in difficult or inaccessible areas. However, there are also risks associated with human welfare if they are misused [22]. 
From the point view of [20], most drone manufacturers are contracted by the military, and it is prudent to check who and where to procure drones from. So, regulators want procurements to be conducted in an ethical manner. They generally want humanitarian organizations to carefully consider the implications of the political context they work in; for instance, regulators do not want drones for humanitarian purposes to be procured from companies that produce weaponized or armed drones.

Restrictions on the private and safe use of airspace:

Overcoming the obstacle of restrictions for the safe use of airspace is what drone manufacturers must ensure. Security is the overarching goal of EU aviation policy and the European Commission clearly pointed out that the use of drones should be based on the principle of zero safety concessions [7]. To ensure that drones can fully be integrated into the airspace without restrictions, manufacturers must consider and tackle factors which can result in the inability to control the drone in mid-air. Users, on the other hand, must also consider the workload of drones during use in spraying or fertilizer contexts, as well as the handling of consignments [7]. Ref. [7] further stressed the fact that drone operations vary widely throughout the world, but the drone regulations of the US and Europe have been blamed for discouraging the development of a commercial drone market suitable to support scientific research at the scale of small agencies.

Restrictions on the private use of drones can be particularly problematic for the use of drones in agriculture. Drones make it possible to take aerial photography of agriculture plots, which provides crucial information, but poses very little risk. Regulations that make it illegal to own drones or take aerial photography of farms would prevent the high potential and low risk use of drones for agriculture [23].

\subsection{Survey Study Results}

Table 6 lists the profile of the interviewees and we present their perspectives on drones and related challenges.

Table 6. Profile of interviewees.

\begin{tabular}{lll}
\hline \# [a] & Role & Institution \\
\hline 1 & $\begin{array}{l}\text { Lecturer at the Department of Agricultural } \\
\text { Economics and Extension }\end{array}$ & University of Cape Coast, Ghana \\
2 & $\begin{array}{l}\text { Head of the Department of Agricultural } \\
\text { Economics and Extension } \\
\text { Professor. Founder of Global-Partners, } \\
\text { which provides drone services in Benin. } \\
\text { Contributor to the development of Benin's } \\
\text { drone regulation }\end{array}$ & University of Cape Coast, Ghana \\
& $\begin{array}{l}\text { Senior Programme Coordinator ICT. } \\
\text { Currently leading the adoption of drones } \\
\text { for agriculture across ACP }{ }^{[b]} \text { countries }\end{array}$ & $\begin{array}{l}\text { Cochnical Centre for Agricultural and Rural } \\
\text { Co-operation ACP-EU (CTA) }\end{array}$ \\
\hline [a] Interviewee and ${ }^{[\mathrm{b}]}$ ACP: Africa, the Caribbean, and the Pacific.
\end{tabular}

From the survey and perspective of the interviewees, drone use in agriculture can have the most impact by letting farmers know whether their farms are under stress or not. However, there is, apparently, difficulty in shipping drones from Europe to Africa because drones have lithium batteries, which are considered as a fire hazard. Those who procure drones from abroad are faced with major challenges when importing them. According to fourth interviewee, in Uganda, there were cases in which drones were seized for 9 months before they were cleared by customs. Moreover, the lack of regulation in Uganda made it difficult to obtain permits from the concerned authorities at that time.

In another instance, persons who had permission to order drones had to go through lengthy paperwork and should make payments not related to registration. When the persons were requested to register the drones, the personnel at the civil aviation authority lacked knowledge on drones and did not see the need for registration. The persons 
had to create the awareness of drones and their functionalities for the aviation authority personnel's themselves.

In most civil aviation authorities, only few government officials are aware of the need for regulations, and, in some cases, a single individual is assigned to deal with the regulation of drones, while a number of experts work on regulations related to manned passenger and cargo planes. At the enforcement level, there is limited knowledge of drones; officers in customs are usually instructed to look for drones and confiscate them if the persons importing them turn out to have no import permits. Knowledge and information sharing are necessary to enable various actors to act effectively when it comes to regulation and enforcement.

In Benin, on the contrary, there are no restrictions on importing drones, except for the need to pay taxes on some types of drones. Benin has introduced a certification program since the second half of 2018 but is facing difficulty in implementing it. The interviewee was wondering how restrictive the process will be after its introduction towards the end of 2018.

Interviewees have also highlighted differences in the regulations of different countries and the need for harmonization among African countries. Countries do not subscribe to one protocol; they are particularly careful as to how much power and freedom they are willing to give in terms of drone operations. Despite the efforts of the African Union $(\mathrm{AU})$, there is limited knowledge and willingness of one African country to learn from the experiences of the others.

Regarding the challenge of private and restricted use of airspace, the private sector has not been proactive and has been unable to present a viable business model to show how it is using drones for their intended purposes. Therefore, a sovereign state may allow or disallow the use of drones according to its peculiar circumstances. For instance, in Kenya, there has been a good collaboration process where all stakeholders were involved, while in Ghana, the business sector is disconnected from policy makers and is generally not involved in policy decision making.

\section{Discussion}

Our analysis of the retrieved regulations for the 15 different African countries reveals that these regulations show about 40 to 85 per cent of the provisions of the International Civil Aviation Organization (ICAO) manual on RPASs. The synthesis of the SLR and the survey study highlight the current obstacles in developing, executing and maintaining drone policies. These are discussed below.

The results of the SLR presented five key challenges to the effective adoption of drones for agriculture. This presents a logical solution regarding how regulations pertaining to drone usage could be created. First, regulations should cover relevant aspects peculiar to respective countries. Second, the regulations should be made considering the potential uses and concerns of the general public. Third, the regulations must be implemented and enforced to make sure unprescribed usage is checked. Fourth, the procurement process and the process of importing drones should be formalized. Finally, the safe use of drones should be guaranteed. It is particularly important to make sure that drones could not be weaponized, and that their airspace restricted.

As stated by two of the interviewees, the major challenge with regard to the enforcement of regulations is the lack of knowledgeable officials—only few officials or individuals within civil aviation authorities are assigned to handle all issues related to drone regulations, and this is inadequate. The majority of personnel within the civil aviation authorities are unaware of regulations about drones; some have very limited knowledge of drones. In the recent study of [24], in which a policy framework for agricultural drones was proposed, a stakeholder that was involved in the development of Uganda's drone regulation was identified, which points to the fact that the stakeholder's involvement in the regulation development process could guide regulators to adopt favorable provisions for using agricultural drones. 
In addition, it requires commitment, willingness and changes in attitudes to enforce the existing regulations. In some countries, like Benin, it may take an incident to happen before they will enforce the regulation. This calls for harmonization of drone policies across Africa; as one interviewee stated, "the core challenge is the harmonization of the policies in the continent versus not ascribing to one single protocol on the continent. For example, EU has its own ICT for agriculture protocol that each member state is able to subscribe to them and you can see how Brexit is becoming difficult simply because of these things, one country coming out of the EU".

The key to tackling the gaps in regulations has to do with the involvement of all relevant stakeholders in the regulatory processes. The private sector needs to be proactive in the development of the regulations; the government must have the good will to involve the private sector. The private sector needs to propose viable business models and explain how they are using or planning to use drones to responsible authorities in order to prevent regulators from making very restrictive regulations. Inclusive innovation in the agrifood sector therefore calls for sustainable business models for Small and Medium-sized Enterprises (SMEs) when it comes to digital technology adoption and implementation. The authors of $[25,26]$ indicate low rates of digital technology adoption for SMEs and many unsuccessful cases of implementation of digital technologies. A general challenge in the procurement or adopting of drones, as mentioned by an interviewee, was that the very people who will be using these drones for their agricultural needs - the small holder farmers-might not have the means to procure them.

It is of interest that the literature we reviewed largely focused on the technology, safety, ethics and regulatory hurdles towards drones, whereas the interviewees seem mainly to focus on the need for skill and awareness among the responsible authorities to enforce regulations, and the need for sustainability and participatory process in defining regulations.

Most countries demand prior approval for purchasing drones. The required special authorization generally requires the specification of the drone and the purpose it will be used for. In addition, the person flying the drone must request approval for flying from the civil aviation authorities. Certification of drones requires that the drone meets the specification of design for which an approval was given. South Africa, Ghana, and Rwanda are among the countries with systems in place for certification.

\section{Research Limitations}

In our search for African countries with drone regulations in place, we were limited to the two online sources indicated in Section 2 because most of the NCAAs websites were not updated, even though drone regulations might have been established in most countries. Our SLR selection of papers specifically targeted studies that could highlight how regulations are impacting drone use in agriculture, thereby leaving out most studies that were drone application-related, or focused on the societal acceptance of drones, etc. Again, it is possible to have included other relevant papers in other databases than Scopus and Web of Science, but, due to time constrains, we could not include other databases in our search. In addition, we had interviewed only four respondents in our survey study, which is not a sufficiently representative sample. However, the fourth respondent had championed the use of drones in agriculture across 21 countries in Africa and he had encountered several concerns, from some entrepreneurs his organization supported in acquiring drones, about how their imported drones were seized by customs or had to go through a cumbersome process of approval for use, due to a lack of regulations. The other respondents were among those that had raised the concerns, but we were limited to the four respondents as our efforts to recruit others for interviewing yielded no results.

\section{Conclusions}

In this paper, we found that a lack of skilled personnel to handle drone regulations and related matters and a lack of proper processes and resources to purchase and import drones were among the main factors that hinder the implementation and enforcement of these existing regulations. Involving the relevant stakeholders in the regulation process 
seems to be key in developing proper regulations. A clear example here is the Kenyan case where a regulation was approved but had to be retracted when some stakeholders raised issues with the regulation.

Commitment on the part of governments is another factor in the implementation and enforcement of regulations. The drone technology promises unique benefits to farmers and, to sustain this innovation, there is the need for inclusive innovation in the sense of: involving the public by way of awareness-raising about the technology, training potential users and farmers on how to handle and operate drones on farms, and developing the needed policy framework with regulators to make the use of agricultural drones safer and more acceptable.

Author Contributions: All authors had contributed one way or another to the production of this paper. The following shows the various contributions made by each author. Conceptualization, M.A., B.T. and A.K.; methodology, B.T. and A.K.; validation, B.T. and A.K.; formal analysis, M.A.; investigation, M.A.; resources, M.A.; data curation, M.A.; writing—original draft preparation, M.A.; writing-review and editing, M.A., B.T. and A.K.; supervision, B.T. and A.K.; project administration, A.K. All authors have read and agreed to the published version of the manuscript.

Funding: There is no reported funding for this research.

Institutional Review Board Statement: Not applicable.

Informed Consent Statement: Informed consent was obtained from all interviewees involved in this study.

Data Availability Statement: Not applicable.

Acknowledgments: We would like to thank all the interviewees for allowing us to interview them, especially the interviewee from CTA for giving us a list of individuals that had faced drone regulatory problems in Africa.

Conflicts of Interest: The authors declare no conflict of interest.

\section{References}

1. Hogan, S.; Kelly, M.; Stark, B.; Chen, Y. Unmanned aerial systems for agriculture and natural resources. Calif. Agric. 2017, 71, 5-14. [CrossRef]

2. Malveaux, C.; Hall, S.G.; Price, R. Using drones in agriculture: Unmanned aerial systems for agricultural remote sensing applications. In 2014 Montreal, Quebec, Canada, 13-16 July 2014; American Society of Agricultural and Biological Engineers: St. Joseph, MI, USA, 2014; p. 1.

3. Tiwari, A.; Dixit, A. Unmanned aerial vehicle and geospatial technology pushing the limits of development. Am. J. Eng. Res. 2015, 4, 16-21.

4. Sylvester, G. E-agriculture in Action: Drones for Agriculture; Food and Agriculture Organization of the United Nations and International Telecommunication Union: Bangkok, Thailand, 2018.

5. Luppicini, R.; So, A. A technoethical review of commercial drone use in the context of governance, ethics, and privacy. Technol. Soc. 2016, 46, 109-119. [CrossRef]

6. Stöcker, C.; Bennett, R.; Nex, F.; Gerke, M.; Zevenbergen, J. Review of the current state of UAV regulations. Remote Sens. 2017, 9, 459. [CrossRef]

7. Tobór, D.; Barcik, J.; Czech, P. Legal aspects of air transport safety and the use of drones. Zesz. Nauk. Transp. Politech. Ślaska 2017, 97, 167-179.

8. Jeanneret, C.; Rambaldi, G. Drone Governance: A Scan of Policies, Laws and Regulations Governing the Use of Unmanned Aerial Vehicles (UAVs) in 79 Countries; CTA: Wageningen, The Netherlands, 2016.

9. Walker, W.E.; Harremoës, P.; Rotmans, J.; van der Sluijs, J.P.; van Asselt, M.B.; Janssen, P.; Krayervon Krauss, M.P. Defining uncertainty: A conceptual basis for uncertainty management in model-based decision support. Integr. Assess. 2003, 4, 5-17. [CrossRef]

10. ICAO. Cir 328 AN/190. Unmanned Aircraft Systems (UAS) Circular; International Civil Aviation Organization: Montreal, QC, Canada, 2011.

11. Wallace, R.J.; Loffi, J.M.; Vance, S.M.; Jacob, J.; Dunlap, J.C.; Mitchell, T.A. Pilot Visual detection of small unmanned aircraft systems (sUAS) equipped with strobe lighting. J. Aviat. Technol. Eng. 2018, 7, 5. [CrossRef]

12. Colomina, I.; Molina, P. Unmanned aerial systems for photogrammetry and remote sensing: A review. ISPRS J. Photogramm. Remote Sens. 2014, 92, 79-97. [CrossRef] 
13. Clothier, R.A.; Greer, D.A.; Greer, D.G.; Mehta, A.M. Risk perception and the public acceptance of drones. Risk Anal. 2015, 35, 1167-1183. [CrossRef] [PubMed]

14. Weibel, R.; Hansman, R.J. An integrated approach to evaluating risk mitigation measures for UAV operational concepts in the NAS. In Infotech@ Aerospace; Aerospace Research Central: Arlington, VA, USA, 2005; p. 6957.

15. NEPAD. High Level African Panel on Emerging Technologies (APET) Report Drones on The Horizon Transforming Africa's Agriculture. 2018. Available online: https://rpas-regulations.com/ (accessed on 12 September 2018).

16. Kitchenham, B.; Brereton, O.P.; Budgen, D.; Turner, M.; Bailey, J.; Linkman, S. Systematic literature reviews in software engineering-a systematic literature review. Inf. Softw. Technol. 2009, 51, 7-15. [CrossRef]

17. Tüzün, E.; Tekinerdogan, B.; Kalender, M.E.; Bilgen, S. Empirical evaluation of a decision support model for adopting software product line engineering. Inf. Softw. Technol. 2015, 60, 77-101. [CrossRef]

18. Hesse-Biber, S.N.; Leavy, P. The Practice of Qualitative Research; SAGE: London, UK, 2010.

19. Rao, B.; Gopi, A.G.; Maione, R. The societal impact of commercial drones. Technol. Soc. 2016, 45, 83-90. [CrossRef]

20. Gilman, D. Unmanned Aerial Vehicles in Humanitarian Response; United Nations Office for the Coordination of Humanitarian Affairs: New York, NY, USA, 2014.

21. Clarke, R.; Moses, L.B. The regulation of civilian drones' impacts on public safety. Comput. Law Secur. Rev. 2014, 30, $263-285$. [CrossRef]

22. Berie, H.T.; Burud, I. Application of unmanned aerial vehicles in earth resources monitoring: Focus on evaluating potentials for forest monitoring in Ethiopia. Eur. J. Remote Sens. 2018, 51, 326-335. [CrossRef]

23. Freeman, P.; Freeland, R. Politics \& technology: US polices restricting unmanned aerial systems in agriculture. Food Policy 2014, 49, 302-311.

24. Ayamga, M.; Tekinerdogan, B.; Kassahun, A.; Rambaldi, G. Developing a policy framework for adoption and management of drones for agriculture in Africa. Technol. Anal. Strateg. Manag. 2020,1-18. [CrossRef]

25. Shepherd, A. Lessons for Sustainability: Failing to Scale ICT4Ag-Enabled Services; CTA: Wageningen, The Netherlands, 2016.

26. de Zegher, J.F.; Iancu, D.A.; Lee, H.L. Designing contracts and sourcing channels to create shared value. Manuf. Serv. Oper. Manag. 2019, 21, 271-289. [CrossRef] 